\title{
INSEGURANÇA EM MEIO URBANO: O ESPAÇO NA MEDIAÇÃO DE OPORTUNIDADES DELITUOSAS
}

\author{
Teresa V. Heitor ${ }^{1}$
}

Resumo: O risco de insegurança em meio urbano, entendido quer como o medo do crime, quer como a falta de adesão ao sistema normativo da sociedade, constitui um factor inibidor da qualidade de vida. Daí decorrem fortes penalizações para a população, condicionando o modo como usufrui o espaço urbano e exerce a sua quotidianidade.

Parte-se do princípio que a ocorrência de delitos em meio urbano está relacionada com a "oportunidade" da acção ser cometida. A oportunidade ocorre do confronto entre o delinquente e o alvo ou vítima, numa situação vulnerável. Neste processo, o espaço urbano constitui-se como um mediador de oportunidades, emitindo informações sobre a situação. A ausência de sinais de vigilância (activa ou passiva) facilita a ocorrência de delitos.

No artigo, analisam-se as condições espaciais responsáveis por fomentar o controlo informal do espaço urbano, i.e., os mecanismos de "vigilância natural", e exploram-se as formas de maximizar os seus efeitos.

$\mathrm{O}$ artigo está organizado em duas partes. Na primeira caracteriza-se o conceito de vigilância natural e as formas de a exercer. Na segunda faz-se uma revisão crítica das diferentes abordagens ao conceito de vigilância natural, focalizada nos trabalhos pioneiros de Jacobs (1962) e Newman (1972). Discute-se as medidas de intervenção e de prevenção por eles sugeridas e introduzem-se as metodologias posteriormente desenvolvidas por Jefferey (1987) e Hillier (1984).

Conclui-se que essa vigilância está relacionada com as condições de interacção física e social presentes no espaço urbano e depende da acção conjunta de vigilantes activos e/ou passivos.

Palavras-chave: insegurança, condições espacio-funcionais, vigilância natural, interacção física e social.

Urban Insecurity: space as a mediator of crime opportunities (Abstract): A range of urban problems is blamed for the decline of the quality of life in our cities and towns, which include the increase of insecurity in core urban settings. Urban insecurity, being the fear of crime or the lack of civilities, has serious implications on the daily life routines and affects the use of public urban space.

\footnotetext{
${ }^{1}$ ICIST, Instituto de Engenharia de Estruturas, Território e Construção - Instituto Superior Técnico - Departamento de Engenharia Civil e Arquitectura - 1049-001 Lisboa; teresa@civil.ist.utl.pt

PSICOLOGIA, Vol. XXI (2), 2007, Edições Colibri, Lisboa, pp. 31-44.
} 
It is assumed that crime occurrence is related to the ease and opportunity to commit the action. Opportunity occurs when the offender meets the victim in a vulnerable circumstance. In this process, urban space plays a fundamental role by emitting information about the circumstance. The lack of (active or passive) surveillance signals increases the opportunity.

This paper intends to relate the spatial components to the informal control of urban space, i.e., "natural surveillance" and to explore how to maximize its effects.

The paper considers two parts: the first one deals with the natural surveillance rationale and how it is realized in space; The second one approaches the debate that followed the publication of the Jacobs (1962) and Newman (1972)'s pioneer work on natural surveillance. Main principles and spatial strategies advocated by Jacobs (1962), Newman (1972), Jefferey (1978) and Hillier (1984) are discussed. It is concluded that natural surveillance is related to social and physical interaction provided by the urban environment, which in turn is established by means of active and/or passive mediators.

Key-words: insecurity, space-use conditions, natural surveillance, physical and social interaction.

\section{Introdução}

Desde a década de 60, muitas das reflexões sobre a cidade contemporânea incidem no processo de desintegração física e de degradação vivencial com que esta se vem defrontando e nas condições necessárias à revitalização da sua imagem.

Apesar de não haver convergência nas soluções a adoptar, é consensual a opinião de que o actual modelo de desenvolvimento urbano, assente em territórios física e socialmente divididos entre centro e periferia, tende a provocar um agravamento na exclusão social de grandes sectores da população. Tal favorece o surgimento de fenómenos de marginalização e de delinquência, de violência e de desestruturação dos factores de convivência, a par da perda do sentido do bem comum e de laços afectivos com o lugar de residência (Wacqant, 1998).

Embora parte significativa da delinquência com incidência no espaço urbano possa ser inserida no quadro da "pequena criminalidade de rua" ou do "delito de oportunidade", o seu efeito sobre a tranquilidade de espírito dos cidadãos potencia e favorece a emergência do medo ${ }^{2}$. Tais sentimentos

\footnotetext{
2 A preocupação com o nível de insegurança urbana moveu o Concelho da Europa a aprovar, em 1992, a "Carta Urbana Europeia sobre Segurança Urbana e a Prevenção de Delinquência". Neste documento, é afirmado que "os cidadãos não podem usufruir plena-
} 
de insegurança traduzem-se em desconfiança e tendem a desencadear respostas defensivas por parte da população que não só interferem nas formas de interacção e de convivência social como condicionam o modo como o espaço urbano é fruído e a quotidianidade exercida.

Com efeito, a emergência de grandes concentrações urbanas e a diluição dos limites que configuravam a cidade tradicional transportaram consigo uma alteração na percepção do medo. Se, como defende Le Goff (1999), na cidade tradicional o perigo estava para lá dos seus limites, na cidade contemporânea este é necessariamente percepcionado a partir do seu interior, já que se trata de um território alargado e difuso na sua organização.

Do confronto com esta realidade ensaiam-se estratégias - quer para controlo de danos, quer para a prevenção dos mesmos ${ }^{3}$ - com o objectivo de inverter a curva ascendente da criminalidade urbana e reforçar o sentimento de segurança entre a população. Tal envolve esforços direccionados quer para o policiamento mais visível e eficaz, de integração e proximidade, com vista à detenção de delinquentes e à protecção da população, quer para a criação de novos instrumentos jurídicos (e.g., leis mais rígidas associadas a penas mais prolongadas), ou para a eliminação das principais fontes de risco.

Contudo, os indicadores estatísticos mostram que o investimento no aumento de forças policiais ou na publicação de legislação não constituem soluções eficazes para o problema. Reconhece-se, pois, que a prevenção é preferível ao controlo de danos.

Estudos nas área da prevenção do crime têm evidenciado o papel do desenho urbano ${ }^{4}$ na redução do risco de insegurança, sugerindo que as condições espacio-funcionais da cidade podem minimizar as oportunidades

mente o direito à cidade se a sua segurança não estiver assegurada e o seu temor da criminalidade não for dissipado".

3 Foucault (1975) explica a origem e manifestação das estratégias disciplinadoras, dando como exemplo os processos adoptados para combater as grandes epidemias que acompanharam a história ocidental: a lepra e a peste negra. Para debelar a lepra, recorreu-se ao isolamento forçado, i.e., à detenção dos infectados em leprosarias localizadas em sítios remotos. A cidade estava a salvo, expulsando o perigo. Quanto à peste negra, a resposta foi outra: a epidemia não se extinguia isolando os doentes, mas disciplinando a cidade, estabelecendo um sistema de controlo rigoroso sobre os seus habitantes, os bens de consumo e as respectivas condições de salubridade. Ao exílio forçado do leproso e ao esforço para controlar a peste correspondem modos distintos de promover a segurança, i.e., a detenção e a prevenção, os quais têm subjacentes desígnios políticos distintos: a comunidade pura e a sociedade disciplinada.

4 Por desenho urbano entende-se o processo de organização do espaço e das actividades humanas à escala da cidade. 
de ocorrência de acções delituosas e contribuir para mitigar o sentimento de insegurança ${ }^{5}$.

O criminologista Charles Murray (1995) defende que a relação que se estabelece entre o espaço físico e o risco de crime é revelada tanto pelo senso comum como pela experiência do quotidiano. Implícito no facto de se evitarem ruas mal iluminadas ou zonas da cidade em declínio, está a percepção da vulnerabilidade do lugar. Esta é considerada menor nas zonas onde ocorre um controlo informal do espaço, i.e., onde os residentes se observam e reconhecem mutuamente e estão dispostos a prestar auxílio, em caso de perigo. Este controlo do espaço é designado na literatura por "vigilância natural" e está relacionado com as condições de interacção física e social presentes no espaço urbano.

No artigo, pretende-se mostrar como actua o mecanismo de "vigilância natural" enquanto agente promotor de controlo espacial: analisam-se os componentes espaciais que o suportam e procura-se explorar as formas de maximizar os seus efeitos. Na primeira parte, é caracterizado o conceito de vigilância natural. Na segunda parte, faz-se uma revisão crítica das diferentes abordagens ao conceito de vigilância natural focalizada nos trabalhos pioneiros de Jacobs (1962) e Newman (1972). Discutem-se as medidas de intervenção e de prevenção por eles sugeridas e introduzem-se as metodologias posteriormente desenvolvidas por Jefferey (1978) e Hillier (1984).

Deliberadamente, não foram considerados os motivos subjacentes às acções delituosas, que poderiam ser pertinentes numa abordagem sociológica. Partindo das manifestações de actividades delituosas como dados fixos do problema, o enfoque é orientado para as implicações funcionais e sociais da forma urbana, que se podem traduzir em comportamentos delituosos. Admite-se, portanto, que a delinquência como fenómeno social é um facto, suportado por informação estatística e factual, que ocorre num espaço vulnerável. A vulnerabilidade do espaço, descrita pelos atributos físicos, revela-se não causal mas provavelmente não arbitrária em relação a atitudes delituosos.

\footnotetext{
${ }^{5}$ É na segunda metade do séc. XIX que se realiza, em França e na Bélgica, a primeira associação empírica entre delinquência e espaço urbano. Com base em informação estatistica relativa a taxas de delinquência, os investigadores identificaram os lugares onde se concentrava o crime e verificaram que a distribuição espacial dos delitos variava segundo o seu tipo. Estudos ingleses desenvolvidos no mesmo período apoiaram as descobertas dos investigadores franco-belgas (Delgado, 1998). No início do séc. XX, Ernest Burgess publica um estudo fundamentado na distribuição espacial de actividades criminosas na cidade de Lawrence, em Kansas, que iria dar origem à Escola de Chicago, também designada por Ecologia Criminal. Nas décadas seguintes, Shaw e Mckay (1931, 1942) dão um importante contributo nesta área, ao elaborarem um quadro descritivo das áreas de delinquência e uma explicação da distribuição ecológica do crime.
} 


\section{Parte 1. O conceito de vigilância natural}

A teoria das estruturas de oportunidade (Dias e Andrade, 1984), desenvolvida no final da década de 60 , mostrou a importância de três factores na ocorrência de actividades delituosas: delinquente, vitíma e situação. Considera que o delinquente tende a actuar de forma racional, em função de custos e de benefícios e de acordo com normas pré-estabelecidas (Brantingham e Brantingham, 1975, 1980, 1981). O seu comportamento-tipo envolve uma fase inicial de avaliação dos prós e contras do acto que pretende cometer: a dimensão dos potenciais ganhos; a facilidade e a oportunidade de cometer o acto e pôr-se em fuga; os riscos de ser reconhecido e/ou detido; as perdas potenciais a que está sujeito, como o tipo e a duração da pena que lhe poderá ser aplicada. A oportunidade ocorre do confronto entre o delinquente e o (potencial) alvo ou vítima quando este se encontra numa situação vulnerável.

Salvo situações excepcionais, o delinquente tende a não actuar em ambientes que envolvam demasiados riscos de ser detectado e impedido de agir com sucesso. No contexto urbano, o risco significa a presença de mecanismos de controlo espacial que impeçam o acesso ao alvo e dificultem a fuga.

Bennet (1989) reforça estas constatações ao analisar o processo de selecção de alvos/vítimas por parte de delinquentes. Tendo entrevistado 128 detidos por assalto a residências ${ }^{6}$ verificou que as suas principais inquietações estavam relacionadas com a possibilidade de serem detectados e com a facilidade de acederem ao alvo pretendido, i.e., obstáculos à intrusão. Os indícios de actividade no interior das habitações, a eventual presença de residentes ou a existência de outras habitações na proximidade foram considerados os principais factores de risco de detecção, enquanto os dispositivos de segurança (e.g., grades, muros, vedações, sistemas de vigilância, alarmes) constituíam-se como obstáculos à intrusão.

Os resultados sugerem que o espaço físico constitui-se como um mediador de oportunidades, emitindo informação sobre a vulnerabilidade da situação e as características dos alvos ou vítimas. Como os presumíveis delinquentes utilizam essas informações para localizar e decidir qual o alvo a atingir, os agentes de controlo espacial, i.e., os sinais de "vigilância" presentes no espaço podem constituir um factor inibidor de eventuais delitos.

\footnotetext{
${ }^{6}$ Os entrevistados eram todos do sexo masculino, sendo que cerca de metade tinha idade inferior a 21 anos. Durante a entrevista, observaram um vídeo com imagens de 36 habitações unifamiliares em 4 zonas urbanas distintas. As imagens tinham sido captadas a partir de um furgão em velocidade lenta, de modo a simular um percurso pedonal. Foi-lhes pedido para avaliarem os níveis de vulnerabilidade das habitações e que identificassem os factores de risco.
} 
Tal pode ser induzido por via de vigilância activa e passiva. A primeira vigilância activa - refere-se àqueles que podem intervir sobre a acção que está a decorrer, i.e., à presença de pessoas e de actividades, enquanto a segunda - vigilância passiva - aplica-se a dispositivos de segurança. Inclui a manipulação de variáveis morfológicas (condições de acessibilidade física e visual) e a instalação sistemas mecânicos ou electrónicos (e.g., gradeamentos, fechaduras blindadas, alarmes, circuitos de vídeo-vigilância).

$\mathrm{O}$ mecanismo de vigilância natural resulta, portanto, do controlo informal do espaço, estabelecido pela acção conjunta de vigilantes activos e passivos.

Parte 2. As condições morfológicas indutoras do mecanismo de vigilância natural

O conceito de "vigilância natural" enquanto factor dissuasor de actividades delituosas surge na década de 60 , no âmbito dos trabalhos desenvolvidos por Jane Jacobs (1961) sobre as condições vivenciais da cidade moderna 7 . Uma década mais tarde, este tema é retomado por Óscar Newman (1972), no quadro da criminologia ambiental, e posteriormente desenvolvido por outros autores.

Através de exemplos quotidianos, Jacobs questiona os modelos urbanísticos seguidos no pós-guerra, relativamente aos efeitos que produzem. A autora procura identificar os factores de desagregação do espaço de vida urbana: aqueles que tornam impossível a realização da urbanidade e os que, correctamente accionados, podem restaurar a vitalidade necessária. Considera que o contacto social é a base de uma convivência urbana tranquila. A ocorrência de actividades delituosas está relacionada com a ausência de mecanismos de vigilância natural decorrente da insuficiência de actividade urbana.

Jacobs defende que a estrutura reticulada suportada por quarteirões ou blocos de dimensão reduzida, a demarcação clara entre os espaços de uso público e privado, a constante irrigação do espaço exterior por actividades contidas no edificado e a integração dos espaços exteriores de estada na

\footnotetext{
${ }^{7}$ Em "The Death and Life of Great American Cities", Jacobs aborda os problemas de desvitalização urbana presentes nas cidades americanas. Considera que são o resultado da aplicação de um modelo de desenvolvimento urbano inadequado que ignora o real funcionamento das cidades: o convívio entre as distintas funções urbanas - morar, trabalhar, passear, comprar, conviver, circular - que constitui a base da vitalidade urbana, matéria-prima da urbanidade. Defende que a vida urbana é regida por actividades e que os espaços que as acolhem devem estabelecer com elas relações de compromisso e aliança.
} 
rede de espaços de circulação constituem, na sua opinião, as bases do funcionamento equilibrado de uma área urbana, assegurando a presença constante de passantes, por ela designados como 'the eyes of the street'.

Jacobs tem sido criticada por confundir percepção de segurança com ocorrência efectiva de actividades delituosas. Linden (1997) acusa-a de fazer uma leitura demasiado simplista da realidade urbana e defende que a vigilância natural não é por si só suficiente para impedir a ocorrência de delitos, visto tratar-se de um fenómeno bastante mais complexo. Van Soomeren (1996) adianta que tal está sobretudo relacionado com a percepção de insegurança por parte da população e com a sua capacidade efectiva de exercer controlo, considerando-o apenas um mediador de coesão social. Considera ainda que o facto de Jacobs considerar que existe uma correlação negativa entre vitalidade urbana/densidade de utilização e a ocorrência de delitos não corresponde à realidade e que tal apenas sucede quando se trata de percepção de insegurança. Para este autor, muitos espaços são percebidos como seguros e na realidade não o são, tal como sucede frequentemente com as zonas centrais das cidades. Tratam-se de áreas onde efectivamente ocorrem vários tipos de marginalidade: violência (Ramsey, 1982), furtos (Poyner, 1983), e vandalismo (Van Dijk e Van Soomeren, 1980) muito embora continuem a ser consideradas seguras pela população, por se tratarem de territórios de uso intenso, dominados pela imprevisibilidade e casualidade dos encontros e pelo desconhecimento mútuo entre os seus utilizadores ${ }^{8}$. Por outro lado, certas zonas urbanas são frequentemente consideradas inseguras, devido à fraca vitalidade exibida, quando efectivamente o não são. As investigações conduzidas por Ramsay (1982) demonstraram ainda que muitos lugares integrados em áreas com níveis elevados de interacção social exibiam níveis elevados de delinquência apesar dos mecanismos de vigilância natural estarem aparentemente garantidos.

Quando, na década de 70, Oscar Newman aborda o problema da vigilância natural dos espaços urbanos introduz o conceito de "espaço defensivo". Este é entendido como a aptidão do espaço para criar zonas de influência territorial, i.e., áreas com capacidade para induzir a acção vigilante dos residentes ${ }^{9}$.

\footnotetext{
8 Já em 1920, a Escola de Criminologia de Chicago, ao estudar a localização espacial das áreas de delinquência juvenil no centro da cidade de Chicago, detectara que os índices de delinquência eram mais altos no centro urbano do que em áreas periféricas (Shaw e Mckay, 1942).

${ }^{9}$ Newman fundamenta o sentido de comunidade na identificação mútua com o habitat e com o uso de espaços comuns, i.e., de laços afectivos com o lugar de residência e na geração de uma rede de solidariedade e interdependência entre os seus membros.
} 
Newman encara a estrutura espacial como uma hierarquia de domínios territoriais ${ }^{10}$. Defende a necessidade de uma delimitação rígida entre territórios que, a não existir, torna o espaço impessoal e anónimo, précipitando reacções emocionais negativas e respostas agressivas, tornando-o, portanto, vulnerável a acções delituosas. Para atingir estas condições, considera fundamental promover a restrição ou a inibição de acesso físico e visual a estranhos. Para tal, advoga o recurso a barreiras físicas ou simbólicas, à monofuncionalidade dos espaços residenciais e à segregação dos espaços por redução de caminhos alternativos que possibilitem eventuais escapatórias $^{11}$.

O trabalho de Newman teve fortes repercussões na prática urbana e arquitectónica e, em particular, na concepção de espaços residenciais. O impacto deveu-se, sobretudo, ao discurso normativo em que se apoiou, essencialmente dirigido para a definição, ou correcção, de soluções conceptuais. Traduzíveis em recomendações, podem ser facilmente organizadas para servirem de guia na programação de conjuntos habitacionais e na elaboração de projectos de edifícios e de espaços envolventes ${ }^{12}$.

Apesar da grande aceitação dos trabalhos de Newman, o conceito de 'espaço defensivo', foi veementemente contestado e condenado por muitos autores. Adams (1973) acusa Newman de ter construído a sua teoria com base em premissas falsas, partindo do princípio de que as 'agressões' são sempre cometidas por estranhos, sem considerar a possibilidade dos próprios residentes estarem envolvidos. Mawby (1977) não só questiona o conceito de 'espaço defensivo' por criar uma cidade rígida e hierarquizada sem articulação funcional, como as medidas propostas para o efectivar. No que se refere ao controlo informal do espaço, argumenta que maximização das

10 Apoiados nestes conceitos, e com o propósito de definir princípios de organização espacial susceptíveis de estimular relações sociais estáveis, Chermayeff e Alexander (1963), estabelecem uma 'anatomia urbana', baseada na separação de actividades por zonas (espaços), fisicamente estruturadas em função de um sistema hierárquico onde, no topo, se encontra o 'urbano-público' e, na base, o 'individual-privado'. Defendem que a clareza e a autonomia destas zonas depende do modo como se estabelecem as ligações entre estes espaços. Sugerem, ainda, que às transições devem corresponder barreiras físicas, tais como mudanças de nível, portões ou dispositivos sonoros ou visuais.

11 Newman também relaciona a implantação dos edifícios, as entradas e o tipo de fenestração com a capacidade de assegurar a vigilância do espaço público. Enquanto agentes de vigilância passiva, contribuem para o apaziguamento da insegurança subjectiva, permitindo a vigilância continuada por parte dos residentes.

12 Veja-se, por exemplo, as disposições e recomendações técnicas publicadas no Reino Unido pelo Department of Environment (DoE 1973) e pelo Great London Council (GLC, 1978), no que se refere aos padrões espaciais e aos princípios de organização dos espaços de domínio público e privado, de separação de tráfego e às soluções propostas para os acessos à habitação. 
condições de visibilidade contribui para diminuir as oportunidades de delito, dado considerar que existe uma forte correlação positiva entre a localização de barreiras físicas, que permitem a ocultação do delinquente, e a ocorrência de delitos.

No final da década de 70, Ray Jeffery ${ }^{13}$ adopta alguns dos princípios defendidos por Jacobs e Newman. Em "Crime Prevention Through Environmental Design" (CPTED) desenvolve uma estratégia para a redução dos delitos de oportunidade, no espaço urbano, através do desenho urbano e da participação da comunidade. Ao longo da década de 80 , vários contributos oriundos da criminologia ambiental vêm reforçar as estratégias difundidas por Jeffery e evidenciar a sua pertinência e eficácia. Actualmente, o CPTED constitui-se como um movimento internacional com uma vertente eminentemente prática, disponibilizando um conjunto de directrizes para apoio à concepção de espaços à escala da cidade e da edificação (e.g., espaços públicos, espaços residenciais, escolas), grelhas multicritérios para a aferição dos diferentes parâmetros a considerar e para avaliação da capacidade de segurança e de vigilância.

As estratégias propostas pelo CPTED partem do princípio que o ambiente urbano pode influenciar o comportamento delituoso de dois modos: fisicamente, proporcionando as condições espaciais onde os indivíduos actuam; socialmente, promovendo as relações sociais a que os indivíduos respondem. Em termos de desenho urbano, investem no controlo informal dos espaços através da criação de mecanismos activos e passivos de vigilância natural e no reforço da componente territorial (Davey, et al. 2005). A participação da comunidade decorre da aposta no desenvolvimento local à escala comunitária, baseado no envolvimento activo da população na gestão e na manutenção dos espaços públicos.

Com Jacobs partilham a aposta na diversidade de usos e na presença continuada de actividade e, consequentemente, de passantes nos espaços públicos. Tal como Newman, defendem que o controlo social dos espaços prómove, no potencial delinquente, a percepção de risco. Mas, ao contrário das estratégias espaciais utilizadas por Newman, consideram que este tipo de controlo deve ser apoiado em boas condições de visibilidade, o que implica a remoção de obstáculos ou barreiras físicas e a presença de sistemas de iluminação eficazes. Alegam ainda que a presença de espaços abandonados e negligenciados conduz à sua subutilização e, portanto, constitui um factor de insegurança ${ }^{14}$. Propõem um investimento na requalificação dos espaços

$13 \mathrm{O}$ conceito de CPTED foi desenvolvido a partir da sua experiência num projecto de requalificação de espaços escolares em Washington DC.

14 Os estudos desenvolvidos por Q. Wilson e George L. Kelling, em 1982, sobre os processos de vandalização dos espaços públicos, designado por "broken windows", exploraram 
públicos de convivência, como condição para a atracção de actividades e para o fomento de socialização. Consideram que a participação da população na formulação do projecto de espaços públicos e na recuperação e manutenção destes espaços é um factor de controlo territorial, na medida em que permite reforçar os laços de identidade e de pertença com o lugar.

$\mathrm{Na}$ década de 80, Hillier, ao abordar as implicações sociais da forma urbana no âmbito da teoria da Sintaxe Espacial, recupera o tema da vigilância natural. Adopta uma perspectiva próxima de Jane Jacobs e critica as propostas de hierarquização espacio-funcional apresentadas por Newman e seguidas pelo CPTED (Hillier e Hanson, 1984; Hillier et al. 1987, Hillier, 1996). Alega que a repartição da cidade por zonas monofuncionais, destinadas a servir grupos específicos da população nega, à partida, a complexidade urbana e que a hierarquização espacial provoca uma subutilização do espaço que conduz a cidade a uma uniformização alienante. Baseado em informação empírica (Hillier et al. 1987, 1989, 2005), acusa-os de utilizar conceitos falaciosos, quando se referem ao sentido de comunidade estabelecido entre residentes, com exclusão de outros grupos, e à delimitação física do seu território. Afirma que tais 'laços afectivos' advêm de relações de vizinhança induzidas pela proximidade e pela partilha de espaços comuns, que não têm necessariamente de estar pré-determinadas ou vinculadas a um espaço fisicamente delimitado.

Hillier defende que a vigilância natural é desenvolvida por todos aqueles que estão presentes num dado momento no espaço público. Considera que o relacionamento entre diferentes grupos da população é fundamental para obter uma estrutura social coesa e integrada, por ele designada como 'comunidade virtual' (Hillier e Hanson, 1984: 132) ${ }^{15}$. Entende que as relações sociais só são relevantes quando se estabelecem espontaneamente e se promovem naturalmente, pois é essa interacção que induz o desenvolvimento de condições de vigilância natural e de controlo social.

Para Hillier, a segurança do espaço urbano, ao depender da presença espontânea e constante de passantes, quer sejam residentes ou estranhos, resulta de um conjunto de factores, designadamente, da capacidade desse espaço ser acessível, i.e., estar integrado nos espaços de domínio público, ser permeável, i.e., directamente relacionado com outros espaços, ser visível, i.e., ser perceptível a partir dos espaços envolventes e facilitar a observação da movimentação dos outros passantes, ser legivel e previsivel, i.e.,

as implicações de indicadores de negligência e de transgressão no uso dos espaços e mostraram a necessidade de promover meios de manutenção efectiva (Heitor, 2001).

15 Esta comunidade constitui-se pela simples co-presença no espaço. A co-presença vincula espaço, corpos, movimento e potencia a interacção face a face. 
permitir um sentido correcto de orientação e gerar actividades, i.e., permitir que os indivíduos desenvolvam práticas quotidianas.

A teoria da sintaxe espacial é suportada por um modelo descritivo, em que a forma urbana é representada, quantificada e interpretada ${ }^{16} \mathrm{em}$ função das relações de acessibilidade física e visual presentes. A quantificação destas relações, também designada por propriedades sintácticas do sistema, permite correlacionar informação espacial com usos e actividades. Com base nesta informação, torna-se possível analisar a distribuição espacial dos padrões de actividade pedonal (movimento e co-presença de passantes), em função da sintaxe espacial. Em particular, os padrões de actividade pedonal fornecem informação acerca do comportamento do sistema enquanto potencial campo de encontro e de interacção entre diferentes grupos de utilizadores e revelam o modo como as relações sociais são estruturadas e construídas, no espaço e pelo espaço, através da configuração espacial em questão. A sintaxe espacial, ao permitir identificar a capacidade de uma configuração urbana gerar movimento, constitui um instrumento eficaz para compreender os efeitos da vigilância natural e estudar padrões de delinquência urbana. Para além disso, permite quantificar as variáveis espaciais, do mesmo modo que as variáveis sociais e económicas normalmente consideradas, e investigar com igual precisão os padrões de crime em áreas distintas ou dentro da mesma área, usando a mesma metodologia de análise. Contudo, é importante frisar que existe uma distribuição irregular da oportunidade de ocorrência das actividades delituosas nas cidades porque estas têm distribuições irregulares de pessoas e actividades. Como já foi anteriormente referido, as áreas centrais apresentam níveis de actividade mais elevados, por isso, as oportunidades também são mais elevadas. Por outro lado, existem vários tipos de delitos de oportunidade com lógicas espaciais próprias: no roubo de via pública, os carteiristas tendem a actuar em zonas movimentadas ou em lugares sobrelotados, enquanto os assaltantes de carros ou de pessoas procuram lugares pouco movimentados.

16 A quantificação destas relações exige a transformação gráfica da planta. Esta transformação, designada por mapa axial, é constituída pelo menor conjunto de linhas que cobrem todo o sistema espacial, no sentido que qualquer espaço é atravessado por, pelo menos, uma dessas linhas. Tal corresponde à imagem de continuidade física e visual experimentada por aqueles que se movem no sistema e a posteriori. O mapa axial permite quantificar dois tipos de relações sintácticas: as relações em que a informação é retirada directamente da representação e aquelas em que é necessário introduzir informação adicional, como é o caso dos padrões de actividade pedonal. A quantificação das relações espaciais é feita com base no grafo axial. Trata-se de um grafo em que os vertices ou nós correspondem às linhas, sendo que dois vértices são adjacentes se e só se as linhas correspondentes se intersectam. O grafo axial contém, assim, informação acerca das conexões de cada linha com todas as outras que constituem o sistema (Heitor, 2001). 
Com efeito, para identificar a influência efectiva do espaço nas actividades delituosas, torna-se necessário obter informação precisa sobre a localização e o tipo do delito e aplicar metodologias de análise espacial capazes de lidar com precisão com as várias dimensões físicas do espaço urbano.

Desde a década de 80 que a metodologia da sintaxe espacial tem sido aplicada em estudos de padrões espaciais de delinquência urbana. Estes estudos mostram a existência de factores morfológicos que colaboram na redução do crime e que podem ser traduzidos, princípios de desenho urbano e em orientações de projecto.

\section{Conclusão}

Partindo do princípio de que, na ocorrência de actividades delituosas está implícita uma oportunidade decorrente de uma situação de vulnerabilidade espacial, analisou-se o conceito de vigilância natural e os modelos físicos e sociais propostos para a sua efectivação.

Comum às abordagens apresentadas está o pressuposto de que a organização do espaço, não sendo neutra face à forma como o espaço é utilizado, constitui a essência da vigilância natural, embora, para que este funcione, seja necessária a presença de vigilantes activos, dispostos a vigiar e a proteger os outros. Divergente é, contudo, o modelo de organização espacial proposto e a composição dos designados agentes de vigilância activa.

A abordagem inicialmente apresentada por Jacobs defende um modelo de cidade suportado por espaços permeáveis em que a vigilância é assegurada por residentes e por passantes, enquanto que Newman e os seus seguidores apoiam-se num modelo de cidade baseado em espaços hierarquizados, com acessos restritos e controlados, nos quais os residentes são os únicos vigilantes activos. Jacobs considera o movimento de passantes como motivo de segurança e Newman como um eventual perigo. Em termos de desenho urbano, o primeiro corresponde à formula clássica do traçado urbano aberto e permeável, baseado na diversidade de usos e de actividades e suportado por quarteirões e ruas acessíveis a todos os passantes, onde é promovido o contacto social e a participação alargada. O segundo apoia-se num traçado urbano inibidor da actividade pedonal, suportado por um sistema de impasses com acessos restritos e controlados, onde não é suposto o passante aceder.

Contudo, as implicações destas duas abordagens não podem ser subestimadas. Com efeito, quem reside numa rua com actividade continuada não tende a desenvolver sentimentos de insegurança quando se depara com um qualquer passante. No entanto, se o mesmo tipo de encontro ocorrer num lu- 
gar onde a presença de passantes é considerada anormal, já se justifica alguma desconfiança ou insegurança. Não só o comportamento é diferente, como as legitimações o são, dadas as circunstâncias espaciais serem distintas.

\section{Referências}

Adams, R. (1973). Review of Defensible Space. Man Environment Systems, 3, pp. 267-268.

Bennet, T. (1989). Burglar's choice of targets. In D. Evans \& D. Herbert (Eds), The Geography of Crime (pp. 176-192). Routledge. New York

Brantingham, P. J. \& Brantingham, P. L. (1975). The Spatial Patterning of Burglary. The Howard Journal, 14 (2), 11-23.

Brantingham, P. J. \& Brantingham, P. L. (1980). Residential Burglary and Urban Form. Criminology Review Yearbook (pp. 475-486) (originally Urban Studies, 12 (3), Oct .1975).

Brantingham, P. J. \& Brantingham, P. L. (Ed.) (1981). Environmental Criminology Beverly Hills: Sage.

Chermayeff, S. \& Alexander, C. (1963). Community and Privacy: Towards a New Architecture of Humanism. Harmondsworth: Penguin.

Davey, C. Wootton, A. Cooper, R. \& Press, M. (2005). Design Against Crime: Extending the Reach of Crime Prevention through Environmental Design. The Security Journal, 18 (2), 89-51.

Delgado, C. (1998). O Cenário do Delito. Dissertação para obtenção do grau de Mestre em Planeamento e Projecto do Ambiente Urbano, Faculdade de Arquitectura do Porto, Universidade do Porto, Porto.

Department of the Environment (1973). Essex Design Guide, DoE, HMSO, London.

Dias, J.F. \& Andrade, M. C. (1984). Criminologia, O Homem Delinquente e a Sociedade Criminógena, Coimbra: Coimbra Editora Ltd.

Foucault, Michel (1975) Surveiller et punir, Paris: NRF, Gallimard, col. Bibliothèque des Histoires (trad. brasileira Vigiar e Punir (1989). Editora Vozes de Petrópolis)

Great London Council (1978). An Introduction of Housing Layout. GLC, London: Architectural Press.

Heitor, T. (2001). A Vulnerabilidade do espaço em Chelas; Uma Abordagem Sintáctica. Textos Universitários de Ciências Sociais e Humanas. Lisboa: Edição da Fundação Calouste Gulbenkian e Fundação para a Ciência e Tecnologia.

Hillier, B. \& Hanson, J. (1984). The Social Logic of Space. Cambridge: Cambridge University Press.

Hillier, B., Burdett, R., Peponis, J. \& Penn, A. (1987). Creating Life: Or, Does Architecture Determine Anything?. Architecture et Comportment / Architecture and Behaviour, 3, 233-250. 
Hillier, B., Grajewski, T., Xu, J., Penn, A. \& Jones, L. (1989). The spatial pattern of crime on the studley estate. London: Unit for Architectural Studies, University College London.

Hillier, B. \& Sahbaz, O. (2005). High resolution analysis of crime patterns in urban street networks: an initial statistical sketch from an ongoing study of a London borough. Proceedings of the Fifth International Space Syntax Symposium, University of Delft 2005; 13-17th June 2005; Conference paper.

Jacobs, J. (1961). The Death and life of Great American Cities The failure of Town Planning. Harmondsworth, Midlesex, England: Penguin Books Ltd.

Jeffery, C. R. (1977). Crime Prevention Through Environmental Design. Beverly Hills, CA: Sage Publications.

Le Goff (1998). Por Amor às Cidades. São Paulo: Editora UNESP.

Linden, R. (1997). Building a Safer Society: Crime Prevention in Residential Environments. Canada Housing and Mortage Corporation.

Mawby, R. I. (1977). Defencible Space: A Theoretical and Empirical Appraisal. Urban Studies, 14, 169-179.

Murray, C. (1995). The physical Environment. In J. Q. Wilson \& J. Petersilia (Eds.), Crime. San Francisco, CA: Institute for Contemporary Studies.

Newman, O. (1972). Defensible Space: Crime Prevention Through Urban Design. McMillan, New York: The Architectural Press.

Ramsay, M. (1982). City-centre Crime: the scope of situational prevention. Research and Planning Unit Paper 10. London: Home Office.

Poyner, B. (1983). Design Against Crime (Beyond Defensible Space) London: Butterworth.

Van Dijk \& Van Soomeren (1980). Vandalism in Amsterdam. Universiteit van Amsterdam.

Shaw, C. R. (1929). Delinquency Areas. Chicago: University of Chicago Press.

Shaw, C. R. \& Mackay H. D. (1931). Social Factors in Juvenile Delinquency. Washington D.C.: Government Printing Office.

Shaw, C. R. \& Mackay H. D. (1942) Juvenil Delinquency in Urban Áreas. Chicago: University of Chicago Press (revised Edition 1969).

Van Soomeren (1987). Safe and Secure Cities. The Physical urban environment and reduction of urban insecurity: a general introduction. Council of Europe, Conference on the Reduction of Urban Insecurity, Barcelona, Nov. 17-20.

Wacquant, L.(1998). La Tentation Pénale en Europe. Actes de la Recherche en Sciences Sociales, Pierre Bourdieu (Director), 124, 3-6. 